\title{
Maintenance therapy for metastatic non-small-cell lung cancer - the role of pemetrexed
}

This article was published in the following Dove Press journal:

Lung Cancer:Targets and Therapy

7 April 2010

Number of times this article has been viewed

\author{
Youval Katz \\ Robert A Somer \\ Cooper University Hospital, \\ Cooper Cancer Institute, \\ University of Medicine and \\ Dentistry of New Jersey/Robert \\ Wood Johnson Medical School, \\ Camden, New Jersey, USA
}

Correspondence: Robert A Somer, MD Cooper Cancer Institute, Medical Oncology Clinical Trials Center, 900 Centennial Blvd Suit M,Voorhees, NJ 08043, USA

Email somer-robert@cooperhealth.edu
Abstract: Over the last several years, we have greatly enhanced our understanding of tumor biology and have now integrated novel and molecular-targeted therapies into front-line treatment for locally advanced and metastatic non-small-cell lung cancer (NSCLC). Despite all the recent advances, the improvement in survival outcomes for these patients has been measured in weeks compared to historical controls. Clinical researchers continue to search for the silver bullet that will allow oncologists to treat lung cancer as a chronic illness and prolong life well beyond the statistical barrier of 1 year for these patients. In that vein, maintenance therapy is emerging as a new treatment option in the metastatic setting. However, there is much controversy over the validity and cost-effectiveness of this modality. Recently, a phase III trial of pemetrexed maintenance versus best supportive care in the setting of metastatic NSCLC following non-progression after 4 cycles of platinum-based doublet therapy showed significant survival outcomes of the treatment group. This article will review the current available treatment options in metastatic NSCLC, including maintenance regimens, with particular attention paid to the recent pemetrexed study.

Keywords: non-small-cell lung cancer, pemetrexed, maintenance therapy

\section{Introduction}

The number of newly diagnosed cases of cancer nationwide approached 1.5 million in $2009 .{ }^{1}$ Lung cancer will account for more than $10 \%$ of these new cases, numbering almost $220,000,{ }^{1}$ more than any other single organ site. Non-small-cell lung cancer (NSCLC) comprises about $85 \%$ of all cases. ${ }^{1} 160,000$ people are expected to die in 2010 from lung cancer, making it the leading cause of cancer death in North America. ${ }^{1}$ Mortality from all cancers has trended downward gradually, but consistently, since 1993. ${ }^{2}$ However, the reduction in the number of deaths from lung cancer has been modest at best due to a variety of factors, including a plateau in the reduction of female lung cancer deaths, but mainly due to the high mortality rate of patients with metastatic disease. ${ }^{3,4}$ One of the major challenges in reducing the mortality associated with NSCLC is the fact that more than $50 \%$ of patients present with metastatic disease at the time of diagnosis. ${ }^{4,5}$ The prognosis in this subset of patients with stage IIIB (with malignant pleural or pericardial effusion) or stage IV disease, remains poor. The revised TNM staging for lung cancer will incorporate these patients into stage IV disease as of January 1, 2010 and will classify them as M1a disease based on their inferior median survival compared to patients with T4 disease ( 8 months versus 13 months). ${ }^{5}$ With a median survival of less than 1 year and a 5-year survival in this population of $3.5 \%,{ }^{4}$ efforts continue at an ever-increasing pace to try and improve this outcome. submit your manuscript | www.dovepress.com

Dovepress
Lung Cancer:Targets and Therapy 2010:1 1-7

(C) 2010 Katz and Somer, publisher and licensee Dove Medical Press Ltd. This is an Open Access article which permits unrestricted noncommercial use, provided the original work is properly cited. 
This decade has seen a proliferation of single-agent and combination regimens in treating metastatic NSCLC, as well as the advent of molecular targeted therapies. One of the chemotherapeutic agents approved for treating metastatic NSCLC is pemetrexed, a novel multitargeted antifolate. ${ }^{6}$ This review will focus on the treatment of metastatic NSCLC, highlighting several landmark trials, including the expanding role of pemetrexed and the emerging data regarding its potential use as maintenance therapy.

\section{First-line therapy for metastatic disease}

A number of agents are currently approved for first-line therapy in stage IIIB or stage IV NSCLC in patients with an ECOG performance status of 0 to 1 . Research dating back more than 20 years first established the concept of platinumbased chemotherapy being superior in overall survival compared to best supportive care (BSC). Rapp et al in 1988 compared platinum-based chemotherapy in advanced NSCLC versus best supportive care in one of the earliest lung cancer trials with a relatively robust sample size. ${ }^{7} \mathrm{~A}$ meta-analysis published by the Non-small Cell Lung Cancer Collaborative Group in 1995 provided more evidence for the potential survival benefit of chemotherapy versus BSC in treating NSCLC. ${ }^{8}$ The ECOG 1594 trial, published by Schiller et al in 2002, confirmed platinum doublet regimens as the standard in first-line therapy for advanced disease. ${ }^{9}$ The trial demonstrated equivalent outcomes in response rates and overall survival comparing cisplatin and paclitaxel with 3 different platinum-based chemotherapy regimens: cisplatin and gemcitabine; cisplatin and docetaxel; or carboplatin and paclitaxel. A pivotal phase III trial published by Scagliotti et al in 2008, originally designed as a non-inferiority trial, compared cisplatin-gemcitabine, a standard first-line regimen for advanced NSCLC, with cisplatin-pemetrexed. ${ }^{10}$ Overall survival for cisplatin-pemetrexed was noninferior to cisplatin-gemcitabine and a median survival of 10.3 months was achieved in both arms. Overall survival was statistically superior for cisplatin-pemetrexed versus cisplatin-gemcitabine in patients with adenocarcinoma ( $\mathrm{n}=847 ; 12.6$ vs 10.9 months, respectively) and large-cell carcinoma histology $(\mathrm{n}=153 ; 10.4$ vs 6.7 months, respectively). However, in patients with squamous cell histology, cisplatin-gemcitabine demonstrated a significant survival benefit versus cisplatin-pemetrexed ( $\mathrm{n}=473$; 10.8 vs 9.4 months, respectively). Already approved as a second-line single-agent therapy in advanced or recurrent NSCLC, pemetrexed was subsequently approved as a first-line agent in combination with cisplatin in NSCLC, non-squamous cell histology. Interestingly, this trial was the first to demonstrate differential efficacy in NSCLC based on tumor histology, presumably due to increased levels of thymidylate synthase in squamous cell tumors. ${ }^{11}$

The addition of targeted therapies to established chemotherapy doublets expanded the arsenal of agents in advanced NSCLC to improve overall survival in select patients who meet specific eligibility criteria. Sandler et al in 2006 demonstrated the success of adding the vascular endothelial growth factor (VEGF) receptor inhibitor bevacizumab to carboplatinpaclitaxel in a phase III trial, ECOG 4599. ${ }^{12,13}$ Superior outcomes were seen in response rates, progression-free survival and overall survival, with an increase in overall survival of 2 months for carboplatin-paclitaxel-bevacizumab versus carboplatin-paclitaxel alone (12.3 vs 10.3 months, respectively). Survival benefits, however, came at a cost of statistically significant increase in toxicities and treatmentrelated deaths. Five deaths were attributed to pulmonary hemorrhage, 5 to complications of febrile neutropenia, 2 each to a cerebrovascular event or gastrointestinal hemorrhage, and 1 to a probable pulmonary embolus. The majority of treatment-related deaths occurred within the first 2 cycles of therapy. The FLEX trial results, published in abstract form by Pirker et al in 2008, added the epidermal growth factor receptor (EGFR) inhibitor cetuximab to the doublet of cisplatin and vinorelbine. ${ }^{14}$ The survival benefit of the group receiving chemotherapy plus cetuximab was irrespective of tumor histology. This regimen is the only combination chemotherapy approved for patients with an ECOG performance status of 2 .

\section{Second-line therapy for metastatic disease}

Several studies have shown the benefits of single-agent chemotherapy in the second-line setting. Combination regimens have proven too toxic in the second-line setting, sometimes with inferior survival compared to single agents. ${ }^{15}$ Currently, 3 drugs are approved for single-agent therapy in metastatic NSCLC in patients with an ECOG performance status of 0 to 2 . The TAX $317^{16}$ and TAX $320{ }^{17}$ trials in 2000 compared docetaxel with BSC and with vinorelbine or ifosfamide, respectively. Both trials demonstrated superior overall survival with single-agent docetaxel as well as improved quality of life in the docetaxel arms. Pemetrexed was approved for second-line therapy after Hanna et al in 2004 found it to be equivalent to docetaxel in terms of response rates, progression-free survival and overall survival. ${ }^{18}$ Additionally, 
pemetrexed therapy had a better toxicity profile, most notably a statistically significant decrease in hospitalization rates for neutropenic fever compared to docetaxel. The EGFR inhibitor erlotinib was approved in late 2004 after it proved superior to placebo in prolonging median overall survival by 2 months. ${ }^{19}$ Response to erlotinib was significantly higher in non-smokers, the presence of adenocarcinoma and EGFR expression. Other subgroups in the study that did not demonstrate these characteristics still did exhibit some response to erlotinib though. Of the 731 patients enrolled in the study, 50\% of them had received 2 or more chemotherapy regimens. The response rate and survival benefit in this group was identical to patients who had been treated with only 1 prior regimen. Based on these results, erlotinib was approved for third-line treatment and remains the only agent in this category. A recent Korean trial published in 2008 also evaluated pemetrexed as a third-line agent, with encouraging results. ${ }^{20}$

\section{A question of timing}

Throughout the past decade, research has sought to address the issue of determining the appropriate length of time to administer chemotherapy. Studies have consistently shown that a short, fixed number of 3 to 4 cycles in the first-line setting provided the greatest balance of overall survival benefit with acceptable levels of toxicity. ${ }^{21,22}$ Treating beyond 4 cycles of first-line chemotherapy has generally increased toxicity and may decrease the likelihood of patients ever receiving second-line agents. Park et al conducted a trial that supports this theory. In 2007, the Korean Cancer Study Group randomly assigned 314 patients with stages IIIB or IV NSCLC who had not progressed after 2 cycles of chemotherapy to receive either 2 or 4 additional cycles of cisplatin-based chemotherapy. ${ }^{23}$ No survival benefit was noted in the group receiving 4 additional cycles. However, 99 (62.7\%) of 158 patients in the 4-cycle arm and 116 (74.4\%) of 156 patients in the 2-cycle arm received second-line chemotherapy, and these values were significantly different $(P=0.026)$. Patients in the 2-cycle arm also had a significantly less toxicity and better recovery of role function compared to the 4-cycle arm.

Only 1 trial demonstrated a survival benefit when continuing first-line platinum-based chemotherapy beyond 4 cycles. Barata et al conducted a trial comparing 4 versus 6 cycles of carboplatin and gemcitabine in patients with stage IIIB or IV NSCLC. ${ }^{4}$ The time to progression was not significantly different between the 2 arms, but overall survival was significantly longer on the 6-cycle arm compared with the 4-cycle arm $(P=0.047)$. The median survival on the 4and 6-cycle treatment arms were 7 months $(95 \%$ confidence interval [CI], 5.9-8.1 months) and 12 months (95\% CI, 9.8-14.2 months), respectively. Overall survival, though noted to be superior on the 6-cycle arm, was not reported in the abstract. Also, the sample size of 220 patients in this trial may not have been adequate to make a definitive statement about the benefits of extending treatment beyond 4 cycles.

Continuing chemotherapy beyond a fixed number of cycles has also been examined in the second-line setting. Specifically, the options include: waiting until disease progression before initiating second-line therapy, which is the standard approach; switching to a second-line regimen after a fixed number of cycles of first-line chemotherapy; or, continuing first-line therapy until disease progression, then switching to a second-line agent. ${ }^{21}$ While many studies have touted improvements in progression-free survival in a variety of dosing schedules, none have shown a statistically significant benefit in overall survival when compared to first- or second-line regimens given in standard fashion. More recent investigations have reinforced this fact. The trial conducted by Fidias et al in 2009 compared immediate with delayed docetaxel after front-line therapy with gemcitabine plus carboplatin in advanced NSCLC. ${ }^{25}$ Although the trial did show a statistically significant increase in progression-free survival, overall survival was not impacted. What is notable in this study is that patients who actually received the docetaxel in the delayed docetaxel arm in had an identical overall survival of 12.5 months compared to patients in the immediate docetaxel arm. This subset analysis raises an interesting question that other authors have also asked: does the timing of the second-line chemotherapy administration matter, or is it simply the exposure of these patients to the second-line regimen that confers a survival benefit? ${ }^{26,27}$ Further exploration of this hypothesis with appropriately designed trials comparing immediate versus delayed second-line chemotherapy should provide a definitive answer.

\section{Maintenance therapy}

A great deal of excitement and controversy has surrounded recent trials testing the concept of maintenance therapy. Since 2001, numerous trials have evaluated the potential role of maintenance therapy in advanced NSCLC with standard chemotherapy and with the newer targeted agents. None of these trials have demonstrated a benefit in overall survival compared to administering second-line therapy at the time of disease progression (Table 1). ${ }^{28-35}$ Overall survival data from the ATLAS trial conducted by Miller et al looking at maintenance bevacizumab with or without erlotinib, is not yet 
mature. ${ }^{36}$ Overall survival results from the SATURN trial conducted by Cappuzzo et al examining the role of maintenance erlotinib versus placebo were recently reported. ${ }^{37-39}$ An overall survival benefit of one month (12 vs 11 months, $P=0.0088$ ) was described, favoring erlotinib over placebo. ${ }^{39}$ However, these data have not yielded any change in clinical practice as of yet, and the issue of maintenance therapy conferring the survival benefit versus the exposure to chemotherapy has not been answered. Currently, 4 to 6 cycles of first-line chemotherapy followed by second-line chemotherapy begun at the time of disease progression remains the preferred method of administration in recurrent or metastatic NSCLC. ${ }^{40}$

Until recently, no trials have examined pemetrexed as maintenance therapy. Given the efficacy, tolerability and ease of administration, it seemed a logical choice for evaluation as a maintenance regimen. Ciuleanu et al published results of their phase III trial data in late 2009 to test this idea. ${ }^{41}$ In this randomized, double-blind, placebo-controlled trial, 663 patients with stage IIIB or IV NSCLC who had not progressed on 4 cycles of platinum-based chemotherapy were randomly assigned in a 2:1 ratio to receive pemetrexed in 21-day cycles plus BSC or placebo plus BSC. Treatment was continued until disease progression. Pemetrexed-containing regimens were not included in the initial platinum doublet options since the study began prior to the trial conducted by Scagliotti et al that led to pemetrexed approval for first-line therapy. ${ }^{10}$ The primary endpoint of this study was progression-free survival. Secondary endpoints included overall survival, objective tumor response rate and safety. The results demonstrated superior progression-free survival in the pemetrexed plus BSC arm compared with placebo plus BSC (4.3 months [95\% CI 4.1-4.7] vs 2.6 months [1.7-2.8]; hazard ratio [HR] 0.50, 95\% CI $0.42-0.61, P<0.0001)$. The secondary endpoint of overall survival also showed pemetrexed plus BSC to be superior to placebo plus BSC (13.4 months [11.9-15.9] vs 10.6 months [8.7-12.0]; HR 0.79, 0.65-0.95, $P=0.012$ ). These outcomes were significant in the non-squamous histology groups. As proven in prior studies, patients with squamous histology did not derive significant benefit from treatment with pemetrexed..$^{10,42}$ Of note, 41 patients $(18 \%)$ in the placebo arm who were unmasked to study treatment at the time of disease progression went on to receive treatment with pemetrexed, at the discretion of the investigator. No survival data were collected on the post-discontinuation patients who went on to receive further treatment, which would be of potential value in comparing this standard treatment approach to maintenance therapy. Based on the results of this trial and the ongoing debate about maintenance therapy in general, recent updates to the NCCN guidelines now include the options of continuing first-line therapy until disease progression or using pemetrexed as maintenance therapy in non-squamous histology until disease progression. ${ }^{40}$ However, these guidelines are all level

Table I Survival data of previous maintenance chemotherapy trials in advanced NSCLC

\begin{tabular}{|c|c|c|c|}
\hline Authors & $\begin{array}{l}\text { Number of patients } \\
\text { randomized }\end{array}$ & TTP/PFS & Median overall survival \\
\hline Socinski et $\mathrm{al}^{28}$ & $\begin{array}{l}\mathrm{n}=230 \text { ( } 4 \text { cycles } \\
\text { carboplatin-paclitaxel } \\
\text { vs continuous treatment } \\
\text { until progression) }\end{array}$ & $\mathrm{N} / \mathrm{A}$ & 6.6 vs $8.5 \mathrm{mos} ; P=0.63$ \\
\hline Belani et $\mathrm{al}^{29}$ & $\mathrm{n}=130$ (paclitaxel vs BSC) & TTP: 38 vs 29 wks; $P=0.124$ & 75 vs 60 wks; $P=0.243$ \\
\hline Giaccone et $\mathrm{al}^{30}$ & $\begin{array}{l}\mathrm{n}=1093 \text { (gefitinib maintenance } \\
500 \mathrm{mg} / \mathrm{d} \text { vs } 250 \mathrm{mg} / \mathrm{d} \text { vs placebo) }\end{array}$ & $\begin{array}{l}\text { TTP: } 5.5 \text { vs } 5.8 \text { vs } 6 \text { mos; } \\
P=0.7633\end{array}$ & 9.9 vs 9.9 vs 10.9 mos; $P=0.456$ \\
\hline Westeel et $\mathrm{al}^{31}$ & $\begin{array}{l}\mathrm{n}=|\mathrm{I}| \mathrm{I} \text { (maintenance } \\
\text { vinorelbine vs observation) }\end{array}$ & PFS: 5 vs 3 mos; $P=0.32$ & I2.3 mos in both groups; $P=0.48$ \\
\hline Brodowicz et $\mathrm{al}^{32}$ & $\begin{array}{l}\mathrm{n}=206 \text { (gemcitabine } \\
\text { maintenance vs BSC) }\end{array}$ & TTP: 3.6 vs 2 mos; $P<0.001$ & 10.2 vs 8.1 mos; $P=0.195$ \\
\hline Gatzemeier et $\mathrm{al}^{33}$ & $\mathrm{n}=\mathrm{I} \mid 72$ (erlotinib vs placebo) & TTP: 23.7 vs 24.6 wks; $P=0.74$ & 43 vs 44.1 wks; $P=0.49$ \\
\hline Kelly et $\mathrm{al}^{34}$ & $n=243$ (gefitinib vs placebo) & PFS: 8.3 vs II.7; $P=0.17$ & 23 vs 35 mos; $P=0.013$ \\
\hline Johnson et $\mathrm{al}^{35}$ & $\mathrm{n}=186(\mathrm{CAl}$ vs placebo $)$ & TTP: 2.8 vs 2.4 mos; $P=0.5$ & II. 4 vs 10.5 mos; $P=0.54$ \\
\hline Miller et $\mathrm{al}^{36}$ & $\begin{array}{l}n=768 \text { (bevacizumab with } \\
\text { or without erlotinib) }\end{array}$ & PFS: 4.8 vs 3.7 mos; $P=0.0012$ & Data not yet mature \\
\hline Cappuzzo et $\mathrm{al}^{37-39}$ & $\mathrm{n}=889$ (erlotinib vs placebo) & $\begin{array}{l}\text { PFS: HR =0.7I [95\% Cl 0.62-0.82]; } \\
P=0.000003\end{array}$ & 12 vs $I I \mathrm{mos} ; P=0.0088$ \\
\hline
\end{tabular}

Abbreviations: $\mathrm{Cl}$, confidence interval; $\mathrm{HR}$, hazard ratio; PFS, progression-free survival;TTP, time to progression. 
2B recommendations, indicating a lack of uniform consensus opinion on this issue.

\section{Future directions in pemetrexed therapy}

In addition to its possible role in maintenance therapy, efforts continue to define how best to apply pemetrexed in treating advanced or metastatic NSCLC based on its novel mechanism as a multitargeted antifolate and its associated pharmacogenomic profile. ${ }^{6}$ Its potent inhibition of thymidylate synthase has been a focus of clinical trials that examined its role in predicting response to pemetrexed. Bepler et al conducted a trial of 52 patients with resectable NSCLC treated with neoadjuvant gemcitabine and pemetrexed. ${ }^{43}$ They evaluated the associated levels of gene expression responsible for metabolism of the respective agents to determine whether or not the levels were predictive for tumor response. Tumor response to chemotherapy was inversely correlated with the level of expression of RRM1 ( $P=0.001$; regulatory subunit of ribonucleotide reductase) and thymidylate synthase $(P=0.006)$. The authors concluded that the reduction in tumor size was greater in patients with low levels of gene expression. Smit et al conducted randomized phase II trial comparing pemetrexed with pemetrexed plus carboplatin in patients with relapsed NSCLC after platinum-based chemotherapy. ${ }^{44}$ They analyzed polymorphisms of thymidylate synthase, the reduced folate carrier, $\gamma$-glutamyl hydrolase, and methylene tetrahydrofolate reductase (MTHF) to elucidate their potential roles as predictive biomarkers. Patients with homozygous mutations for MTHFR C677T had a significantly increased progression-free survival compared with patients with wild-type or heterozygous mutations $(P=0.03)$. Patients with homozygous mutations for MTHFR 1298C had a lower progression-free survival compared with those who had wild-type or heterozygous mutations, but did not quite reach statistical significance $(P=0.06)$. Progression-free survival did not differ for the other genotypes tested. The authors did not find any correlation between high and low thymidylate synthase expression genotype and tumor histology or clinical outcome. A more relevant clinical predictor of response to pemetrexed may be to analyze thymidylate synthase expression in the tumor itself. Further studies are needed to assess this possibility. Other investigators have also studied pemetrexed and its potential synergy with other agents to try and predict tumoral response at the molecular level. Giovannetti et al examined pemetrexed and its synergy in vitro with erlotinib ${ }^{45}$ and gemcitabine ${ }^{46}$ in separate studies against NSCLC tumor cells. Both experiments showed synergistic cytotoxicity and enhanced apoptosis. These results, combined with predictive biomarkers for pemetrexed efficacy, provide a powerful foundation for future research to better tailor therapy for patients with advanced NSCLC.

Pemetrexed has clearly been proven an effective and well-tolerated therapy in the treatment of advanced NSCLC in both first- and second-line settings. Its role in maintenance therapy is still being defined, as is the concept of maintenance therapy as a whole. However, without a clearly defined advantage over administering second-line therapy at the time of disease progression, maintenance regimens are an expense that may not be justified in this emerging era of cost-conscious health care. With so many trials failing to show any significant overall survival benefits, one wonders how many times this well can be tapped. Meanwhile, the goal of personalizing therapy appears to hold the key to improving outcomes for patients in future treatment paradigms.

\section{Disclosures}

The authors declare no conflicts of interest.

\section{References}

1. Jemal A, Siegel R, Ward, E, Hao Y, Xu J, Thun MJ. Cancer Statistics, 2009. CA Cancer J Clin. 2009;59:225-249.

2. Heron M, Hoyert DL, Murphy SL. Division of Vital Statistics. Deaths: Final Data for 2006. National Vital Statistics Reports. 2009;57(14).

3. National Cancer Institute, Cancer Trends Progress Report - 2007 Update. http://progressreport.cancer.gov/doc_detail.asp?pid=1\&did= $2007 \&$ chid=76\&coid=729\&mid=\#trends.

4. Horner MJ, Ries LAG, Krapcho M, et al. (eds). SEER Cancer Statistics Review, 1975-2006, National Cancer Institute. Bethesda, MD, http://seer.cancer.gov/csr/1975_2006/, based on November 2008 SEER data submission, posted to the SEER web site 2009.

5. Groome PA, Bolejack V, Crowley JJ, et al IASLC International Staging Committee; Cancer Research and Biostatistics; Observers to the Committee; Participating Institutions. The IASLC Lung Cancer Staging Project: validation of the proposals for revision of the T, N, and $\mathrm{M}$ descriptors and consequent stage groupings in the forthcoming (seventh) edition of the TNM classification of malignant tumours. J Thorac Oncol. 2007;2:694-705.

6. Chuana S, Habecka LL, Mendelsohna LG, VJ, Schultz RM. Multiple folate enzyme inhibition: mechanism of a novel pyrrolopyrimidine-based antifolate LY231514 (MTA). Advan Enzyme Regul. 1998;38:135-152.

7. Rapp E, Pater JL, Willan A, et al. Chemotherapy can prolong survival in patients with advanced non-small-cell lung cancer - Report of a Canadian multicenter randomized trial. J Clin Oncol. 1988:6:633-641.

8. Non-Small Cell Lung Cancer Co-operative Group. Chemotherapy in non-small cell lung cancer: a meta-analysis using updated data on individual patients from 52 randomized clinical trials. BMJ. 1995;311:899-909.

9. Schiller JH, Harrington D, Belani CP, et al; for the Eastern Cooperative Oncology Group. Comparison of Four Chemotherapy Regimens for Advanced Non-Small-Cell Lung Cancer. N Engl J Med. 2002;346:92-98. 
10. Scagliotti GV, Parikh P, von Pawel J, et al. Phase III study comparing cisplatin plus gemcitabine with cisplatin plus pemetrexed in chemotherapy-naïve patients with advanced-stage non-small-cell lung cancer. J Clin Oncol. 2008;26:3543-3551.

11. Ceppi P, Volante M, Saviozzi S, et al. Squamous cell carcinoma of the lung compared with other histiotypes shows higher mRNA and protein levels for thymidylate synthase. Cancer. 2006;107:1589-1596.

12. Johnson DH, Fehrenbacher L, Novotny WF, et al. Randomized phase II trial comparing bevacizumab plus carboplatin and paclitaxel with carboplatin and paclitaxel alone in previously untreated locally advanced or metastatic non-small-cell lung cancer. J Clin Oncol. 2004;22:2184-2191.

13. Sandler A, Gray R, Perry MC, et al. Paclitaxel-carboplatin alone or with bevacizumab for non-small-cell lung cancer. $N$ Engl J Med. 2006;355:2542-2550.

14. Pirker R, Szczesna A, von Pawel J, et al. FLEX: A randomized, multicenter, phase III study of cetuximab in combination with cisplatin/ vinorelbine $(\mathrm{CV})$ versus $\mathrm{CV}$ alone in the first-line treatment of patients with advanced non-small cell lung cancer (NSCLC). Proceedings ASCO. 2008; May 20:Abstr 3.

15. Smith IE, O'Brien MER, Talbot DC, et al. Duration of chemotherapy in advanced n-small-cell lung cancer: A randomized trial of three versus six courses of mitomycin, vinblastine, and cisplatin. J Clin Oncol. 2001;19:1336-1343.

16. Shepherd F, Dancey J, Ramlau R, et al. A prospective randomized trial of docetaxel (Taxotere) versus best supportive care in patients with non-small-cell lung cancer previously treated with platinum-based chemotherapy. J Clin Oncol. 2000;18:2095-2103.

17. Fossella FV, DeVore R, Kerr RN, et al. Randomized phase III trial of docetaxel versus vinorelbine or ifosfamide in patients with advanced non-small-cell lung cancer previously treated with platinum-containing chemotherapy regimens. J Clin Oncol. 2000;18:2354-2362.

18. Hanna N, Shepherd FA, Fossella FV, et al. Randomized phase III trial of pemetrexed versus docetaxel in patients with non-small-cell lung cancer previously treated with chemotherapy. J Clin Oncol. 2004;22:1589-1597.

19. Shepherd FA, Pereira JR, Ciuleanu T, et al; for the National Cancer Institute of Canada Clinical Trials Group. Erlotinib in previously treated non-small-cell lung cancer. $N$ Engl J Med. 2005;353:123-132.

20. Sun JM, Lee KW, Kim JH, et al. Efficacy and toxicity of pemetrexed as a third-line treatment for non-small cell lung cancer. Jpn J Clin Oncol. 2009;39:27-32.

21. Soon Y, Stockler MR, Askie L, et al. Duration of chemotherapy for advanced non-small-cell lung cancer: A systematic review and metaanalysis of randomized trials. J Clin Oncol. 2009;27:3277-3283.

22. von Plessen C, Bergman B, Andresen O, et al. Palliative chemotherapy beyond three courses conveys no survival or consistent quality-of-life benefits in advanced non-small-cell lung cancer. Br J Cancer. 2006;95:966-973.

23. Park JO, Kim SW, Ahn JS, et al. Two versus four additional cycles in patients who are non-progressive after two cycles of platinum-based chemotherapy and its clinical implications for future management of non-small cell lung cancer: A prospective randomized phase III trial by the Korean Cancer Study Group. J Clin Oncol. 2007;25:5233-5239.

24. Barata F, Parente B, Teixeira E, et al. Optimal duration of chemotherapy in non-small cell lung cancer: multicenter, randomized, prospective clinical trial comparing 4 vs. 6 cycles of carboplatin and gemcitabine. J Thorac Oncol. 2007;2(Suppl 4):S666.

25. Fidias PM, Dakhil SR, Lyss AP, et al. Phase III study of immediate compared with delayed docetaxel after front-line therapy with gemcitabine plus carboplatin in advanced non-small-cell lung cancer. J Clin Oncol. 2009;27:591-598.

26. Socinski MA. Re-evaluating duration of therapy in advanced non-small-cell lung cancer: is it really duration or is it more about timing and exposure? J Clin Oncol. 2009;27:20:3268-3270.

27. Schiller JH. Duration of chemotherapy for metastatic non-small-cell lung cancer: more may be better after all. J Clin Oncol. 2009;27:20: $3265-3267$
28. Socinski MA, Schell MJ, Peterman A, et al. Phase III trial comparing a defined duration of therapy versus continuous therapy followed by second-line therapy in advanced-stage IIIB/IV non-small-cell lung cancer. J Clin Oncol. 2002;20:1335-1343.

29. Belani CP, Barstis J, Perry MC, et al. Multicenter, randomized trial for stage IIIB or IV non-small-cell lung cancer using weekly paclitaxel and carboplatin followed by maintenance weekly paclitaxel or observation. J Clin Oncol. 2003;21:2933-2939.

30. Giaccone G, Herbst RS, Manegold C, et al. Gefitinib in combination with gemcitabine and cisplatin in advanced non-small-cell lung cancer: a phase III trial - INTACT 1. J Clin Oncol. 2004;22:777-784.

31. Westeel V, Quoix E, Moro-Sibilot D, et al; for the French Thoracic Oncology Collaborative Group (GCOT). Randomized study of maintenance vinorelbine in responders with advanced non-small-cell lung cancer. J Natl Cancer Inst. 2005;97:499-506.

32. Brodowicz T, Krzakowski M, Zwitter M, et al; for the Central European Cooperative Oncology Group (CECOG). Cisplatin and gemcitabine first-line chemotherapy followed by maintenance gemcitabine or best supportive care in advanced non-small cell lung cancer: a phase III trial. Lung Cancer. 2006;52:155-163.

33. Gatzemeier U, Pluzanska A, Szczesna A, et al. Phase III study of erlotinib in combination with cisplatin and gemcitabine in advanced non-small-cell lung cancer: the Tarceva Lung Cancer Investigation Trial. J Clin Oncol. 2007;25:1545-1552.

34. Kelly K, Chansky K, Gaspar LE, et al. Phase III trial of maintenance gefitinib or placebo after concurrent chemoradiotherapy and docetaxel consolidation in inoperable stage III non-small-cell lung cancer: SWOG S0023. J Clin Oncol. 2008,26:2450-2456.

35. Johnson EA, Marks RS, Mandrekar SJ, et al. Phase III randomized, double-blind study of maintenance CAI or placebo in patients with advanced non-small cell lung cancer (NSCLC) after completion of initial therapy (NCCTG 97-24-51). Lung Cancer. 2008;60: 200-07.

36. Miller VA, O'Connor P, Soh C, Kabbinavar F; for the ATLAS Investigators. A randomized, double-blind, placebo-controlled, phase IIIb trial (ATLAS) comparing bevacizumab (B) therapy with or without erlotinib (E) after completion of chemotherapy with B for first-line treatment of locally advanced, recurrent, or metastatic non-small cell lung cancer (NSCLC). J Clinical Oncol, ASCO Annual Meeting Proceedings (Post-Meeting Edition). 2009;27(18S) (June 20 Suppl): LBA8002.

37. Cappuzzo F, Coudert BP, Wierzbicki R, et al; on behalf of the SATURN investigators. SATURN: a double-blind, randomized, phase III study of maintenance erlotinib versus placebo following progression with firstline platinum-based chemotherapy in patients with advanced NSCLC. $J$ Clin Oncol, ASCO Annual Meeting Proceedings (Post-Meeting Edition). 2009;27(15S) (May 20 Suppl):8001.

38. Cappuzzo F, Coudert BP, Wierzbicki R, et al; on behalf of the SATURN investigators. Efficacy and safety of erlotinib as first-line maintenance in NSCLC following non-progression with chemotherapy: results from the phase III SATURN study. 13th World Conference on Lung Cancer (WCLC); August 1, 2009:Abstract A2.1.

39. Cappuzzo F, Coudert B, Wierzbicki R, et al. 22LBA Overall survival analyses from the SATURN phase III placebo-controlled study of erlotinib as first-line maintenance therapy in advanced non-small-cell lung cancer (NSCLC). Eur J Cancer. 2009;7(Suppl 3):13.

40. The NCCN Clinical Practice Guidelines in Oncology ${ }^{\mathrm{TM}}$ Non-Small Cell Lung Cancer (Version 2.2009). (C) 2009 National Comprehensive Cancer Network, Inc. NCCN.org. Accessed Oct 28, 2009.

41. Ciuleanu T, Brodowicz T, Zielinski C, et al. Maintenance pemetrexed plus best supportive care versus placebo plus best supportive care for non-small-cell lung cancer: a randomised, double-blind, phase 3 study. Lancet. 2009;374:1432-1440.

42. Peng G, Zinner RG, Wang Y, et al. Comparison of patient outcomes stratified by histology among pemetrexed (P)-treated patients (pts) with stage IIIB/IV non-small cell lung cancer (NSCLC) in two phase II trials. Proceedings ASCO. 2008; May 20: Abstr 8096. 
43. Bepler G, Sommers KE Cantor A, et al. Clinical efficacy and predictive molecular markers of neoadjuvant gemcitabine and pemetrexed in resectable non-small cell lung cancer. J Thorac Oncol. 2008;3:1112-1118.

44. Smit EF, Burgers SA, Biesma B, et al. Randomized phase II and pharmacogenetic study of pemetrexed compared with pemetrexed plus carboplatin in pretreated patients with advanced non-small-cell lung cancer. J Clin Oncol. 2009;27:2038-2045.

45. Giovannetti E, Mey V, Nannizzi S, et al. Cellular and pharmacogenetics foundation of synergistic interaction of pemetrexed and gemcitabine in human non-small-cell lung cancer cells. Mol Pharmacol. 2005;68:110-118.
46. Giovannetti E, Lemos C, Tekle C, et al. Molecular mechanisms underlying the synergistic interaction of erlotinib, an epidermal growth factor receptor tyrosine kinase inhibitor, with the multitargeted antifolate pemetrexed in non-small-cell lung cancer cells. Mol Pharmacol. 2008;73:1290-1300.

\section{Publish your work in this journal}

Lung Cancer: Targets and Therapy is an international, peer-reviewed, open access journal focusing on lung cancer research, identification of therapeutic targets and the optimal use of preventative and integrated treatment interventions to achieve improved outcomes, enhanced survival and quality of life for the cancer patient. Specific topics covered in the journal include:

\section{Dovepress}

Epidemiology, detection and screening; Cellular research and biomarkers; Identification of biotargets and agents with novel mechanisms of action; Optimal clinical use of existing anticancer agents, including combination therapies; Radiation and surgery; Palliative care; Patient adherence, quality of life, satisfaction; Health economic evaluations.

Submit your manuscript here: http://www.dovepress.com/lung-cancer-targets--therapy-journal 